\title{
TEMPERATURE RECONSTRUCTIONS IN THE PACIFIC OCEAN FROM MASSIVE CORALS (PORITES SP. AND DIPLOASTREA SP.)
}

\author{
M. CANESI ${ }^{1,2}$, E. DOUVILlE $^{1}$, P. MONTAGNA $^{3}$,
} L. Bordier ${ }^{1}$, S. CAQUiNEAU ${ }^{4}$, E. PONS-BRANCHUS ${ }^{1}$, G. IWANKOW $^{5}$, D. ALLEMAND ${ }^{2}$, S. REYNAUD $^{2}$

${ }^{1}$ LSCE (CEA-CNRS-UVSQ), Gif-sur-Yvette, France

(* correspondence :marine.canesi@lsce.ipsl.fr)

${ }^{2}$ Centre Scientifique de Monaco (CSM), Monaco

${ }^{3}$ Istituto di Scienze Marine (CNR), Bologna, Italy

${ }^{4}$ LOCEAN (IRD-CNRS-UPMC-MNHN) Bondy, France

${ }^{5}$ CRIOBE (CNRS-EPHE-UPVD), Perpignan, France

Over the last centuries, paleoclimate reconstructions of the intense ocean warming events that led to large bleaching episodes, can help improving the ability of climate models to predict the anthropogenic impacts on tropical reef ecosystems. Consequently, it is critical to obtain reliable, multi-decadal and centennial sea surface temperature (SST) reconstructions using accurate and precise temperaturesensitive proxies from calcifying organisms, such as tropical corals. $\mathrm{Sr} / \mathrm{Ca}$ and $\mathrm{Li} / \mathrm{Mg}$ ratios in scleractinian corals are robust tools for reconstructing paleo-seawater temperature variations and, recently, they have been combined in a multiproxy approach to overcome the intrinsic limitations of both proxies and obtain higher-confidence reconstructions.

In this study, we investigated the elemental composition of the topmost portion of 40 modern tropical corals of the Porites and Diploastrea genera collected during Tara-Pacific Expedition for various hydrological contexts of the Pacific Ocean. We obtained $\mathrm{Sr} / \mathrm{Ca}$, Li/Mg and multi-proxy vs. SST calibrations. Overall, multi-element and mix-genera approachs improve the reliability of reconstructed SST.

We applied the new calibrations on Porites sp. and Diploastrea sp. coral colonies collected in Palau archipelago, in the western Pacific Ocean. These proxy-based SST reconstructions allowed to (1) compare the quality of the SST-calibrations developed in this study on two coral genera, and (2) investigate the geochemical response of Palau's corals to thermal stress.

Coral-derived SST based on Diploastrea sp. spanning the last 135 years indicate an increase in frequency of El Niño Southern Oscillation events since 1940s occurring in Palau. Nevertheless, differences remain in the reconstructed longterm trends and amplitude of the temperature, depending on which genus, temperature proxy and SST-calibration is considered. 